\title{
Primary chylous ascites in children: Rare cause of a common presentation
}

Juanitha George ${ }^{1}$, *Shravan Kanaparthi ${ }^{1}$, Shrikiran Aroor ${ }^{1}$, Suneel C Mundkur ${ }^{1}$, Sowmya Shashidhara ${ }^{1}$, Kalyan Chakravarthy Konda ${ }^{1}$

Sri Lanka Journal of Child Health, 2019; 48(4): 359-360

DOI: http://dx.doi.org/10.4038/sljch.v48i4.8837

(Keywords: Chylous ascites, paediatrics, malnutrition, lymph, hypoalbuminaemia)

\section{Introduction}

Primary chylous ascites (CA) is a rare entity seen in neonates and infants secondary to lymphatic dysplasia, leading to chylous leak from lymphatics ${ }^{1}$.

\section{Case report}

An 11 month old child presented with a four month history of inadequate weight gain along with a two month history of abdominal distension. There was no history of fever, vomiting, diarrhoea or decreased urine output. Her length $(62 \mathrm{~cm})$ was $85 \%$ of the expected and weight (6.2kg with oedema) was $69 \%$ of the expected suggestive of a grade II proteinenergy malnutrition. Examination revealed pallor, alopecia, bilateral pitting pedal oedema, abdominal distension, dilated veins and no organomegaly. Vitals and other systemic examinations were normal.

Blood investigations revealed hypoalbuminaemia $(1.78 \mathrm{~g} / \mathrm{dl})$ with normal counts, mild hypocalcaemia $(8.7 \mathrm{mg} / \mathrm{dl})$, normal renal function tests, normal liver enzymes and normal prothrombin time. Urinalysis, serum lipid profile, serum amylase and serum lipase were normal. Gastric lavage samples tested for acidfast bacilli and polymerase chain reaction (PCR) were negative.

Ultrasonography (USG) of abdomen revealed gross ascites. Echocardiography, portal and hepatic vein Doppler were normal. Contrast-enhanced computed tomography (CECT) of the abdomen and pelvis showed gross ascites with circumferential wall thickening of the long segment of small bowel loops and no abdominal mass or lymphadenopathy. A $99 \mathrm{mTc}-\mathrm{SC}$ lymphoscintigraphy was suggestive of a lacteal leak with no evidence of lymphatic obstruction. Ascitic tap analysis revealed milky fluid

${ }^{1}$ Kasturba Medical College, Manipal, Mahe, India *Correspondence: shravan.1354@gmail.com

orcid.org/ 0000-0001-9429-2902

(Received on 21 March 2018: Accepted after revision on 18 May 2018)

The authors declare that there are no conflicts of interest

Personal funding was used for the project.

Open Access Article published under the Creative

Commons Attribution CC-BY CC (i) License with high triglyceride levels (2724 mg/dl). Glucose, adenosine deaminase (ADA), amylase and lactate dehydrogenase (LDH) levels were normal. Ascitic fluid cultures and PCR for tuberculosis were negative. Secondary causes of a CA, like malignancy, post-operative, radiation, blunt injury of abdomen, hepatic cirrhosis, portal vein thrombosis and nephrotic syndrome were ruled out.

She was started on a high protein, low fat diet with medium chain triglyceride (MCT) supplementation. Follow up at 2 months showed a significant decrease in the abdominal distension with improved serum albumin $(3.07 \mathrm{~g} / \mathrm{dl})$.

\section{Discussion}

CA is characterised by accumulation of chyle in peritoneal cavity. Primary CA is due to a structural abnormality of the lymphatic vessels (hypoplasia, dysplasia or lymphangiectasia) within the peritoneum $^{2-4}$. An incidence of 1 in 20,000 admissions to a tertiary care centre was reported in the literature ${ }^{5}$. Secondary causes of chylous ascites include obstruction to the duct at the base of mesentery, direct leak of chyle through a lymphoperitoneal fistula, malignancy, post-operative, radiation, tuberculosis, filariasis, pancreatitis, sarcoidosis, pericarditis, blunt injury of abdomen, hepatic cirrhosis, drugs (calcium channel blockers, Sirolimus) portal vein thrombosis or nephrotic syndrome ${ }^{2,4}$. Congenital chylous ascites is associated with Klippel-Trenaunay and Yellow-Nail syndrome ${ }^{2,4}$.

Loss of chyle into the peritoneal cavity results in a significant loss of protein and fat, manifested by hypoproteinaemia, oedema, steatorrhoea, asthenia and tetany ${ }^{4}$. Increased susceptibility to infections due to lymphocyte loss and hypogammaglobulinaemia is seen. Bioavailability of certain drugs (digoxin, amiodarone, cyclosporine) may be altered ${ }^{2}$.

Diagnosis can be made by clinical features manifesting as abdominal distension, vomiting and diarrhoea. Blood investigations show hypoproteinaemia with normal counts ${ }^{6}$. Ascitic tap most often shows milky fluid with high triglyceride $(>200 \mathrm{mg} / \mathrm{dl})$, lactate dehydrogenase $(110-200$ IU/L), glucose $(<100 \mathrm{mg} / \mathrm{dl})$, serum-ascites albumin gradient $(<1.1 \mathrm{gm} / \mathrm{dl})$, total protein $(2.5$ and $7 \mathrm{~g} / \mathrm{dl})$ 
and cell count $(>500$ with lymphocytic predominance $)^{7}$. However, as the nature of the fluid is also dependant on the diet of the child, it is recommended to administer a high-fat diet before the test ${ }^{8}$. Pseudochylous ascites due to degenerating cells with normal triglyceride levels should be ruled out $^{2}$.

Computed tomography (CT) is useful in identifying malignancies and pathological intra-abdominal lymph nodes. Lymphoscintigraphy is used to assess the functioning of the lymphatic transport system. Lymphangiography is considered the gold standard in detecting lymphatic obstruction. However, its use has seen a declining trend as non-invasive diagnostic imaging has become more available ${ }^{2}$.

The mainstay of treatment is conservative. The goal is to decrease chyle production and flow which in turn results in closure of the chylous leak. Improving the nutrition and correcting the underlying disorder are other goals of therapy ${ }^{2,4}$. A high protein and lowfat diet with the addition of medium chain triglycerides (MCTs) are recommended. MCTs bypass the lymphatics as they are not re-esterified within the intestinal cells and thus enter the portal system directly ${ }^{2}$. They are transported as free fatty acids and glycerol by the portal vein into the liver ${ }^{2}$. Supplements with fat-soluble vitamins are required ${ }^{9}$. Paracentesis can be used as a temporary measure to decrease dyspnoea and abdominal discomfort from ascites ${ }^{4}$. Total parenteral nutrition for prolonged periods bypasses the bowel and helps in reducing the lymphatic pressure ${ }^{4}$. Octreotide (by decreasing the bowel blood flow) may relieve the symptoms ${ }^{2,4}$. In cases resistant to the above management, surgical exploration (for benign histologic cause) or peritoneo-venous shunt can be attempted ${ }^{4}$.

Chylous ascites is a rare cause of a common presentation (abdominal distension/ascites). It often requires extensive evaluation to arrive at the diagnosis and to exclude secondary causes. Timely diagnosis and treatment improve the morbidity and mortality of the condition.

\section{References}

1. Campisi C, Bellini C, Eretta C, Zilli A, da Rin E, Davini D, et al. Diagnosis and management of primary chylous ascites. Journal of Vascular Surgery 2006; 43(6): 1244-8. https://doi.org/10.1016/j.jvs.2005.11.064 PMid: 16765248

2. Al-busafi SA, Ghali P, Deschênes M, Wong P. Chylous ascites: Evaluation and management. ISRN Hepatology 2014 (2014). Article ID 240473.
3. Mouravas V, Dede O, Hatziioannidis H, Spyridakis I, Filippopoulos A. Diagnosis and management of congenital neonatal chylous ascites. Hippokratia 2012; 16(2): 175-80.

PMid: 23935276 PMCid: PMC3738422

4. Aalami OO, Allen DB, Organ CH. Chylous ascites: A collective review. Surgery 2000; 128(5):761-78.

https://doi.org/10.1067/msy.2000.109502

PMid: 11056439

5. Press OW, Press NO, Kaufman SD. Evaluation and management of chylous ascites. Annals of Internal Medicine 1982; 96(3): 358-64.

https://doi.org/10.7326/0003-4819-96-3-

358

PMid: 7059101

6. Cochran WJ, Klish WJ, Brown MR, Lyons JM. Chylous ascites in infants and children: a case report and literature review. Journal of Pediatric of Gastroenterology and Nutrition 1985; 4:668-73. https://doi.org/10.1097/000051761985080 00-00031

7. Cardenas A, Chopra S. Chylous ascites. American Journal of Gastroenterology 2002; 97(8):1896-900. https://doi.org/10.1016/S00029270(02)04 268-5

8. Kassem R, Rajab A, Faiz A, Kumar SY, John SA, Taher O. Chylous ascites in an infant - Treated surgically with fibrin glue after failed medical treatment - A case report. Journal of Pediatric Surgery Case Reports 2017; 19:25-7. https://doi.org/10.1016/j.epsc.2017.02.002

9. Ohri SK, Patel T, Desa LA, Spencer J. The management of postoperative chylous ascites. A case report and literature review Journal of Clinical Gastroenterology 1990; 12(6):693-7.

https://doi.org/10.1097/000048361990120 00-00021 